\title{
Occurrence of intestinal parasites in pigs in Poland - the influence of factors related to the production system
}

\author{
Maciej Kochanowski ${ }^{1}$, Jacek Karamon ${ }^{1}$, Joanna Dąbrowska ${ }^{1}$, \\ Arkadiusz Dors $^{2}$, Ewelina Czyżewska-Dors ${ }^{2}$, Tomasz Cencek ${ }^{1}$ \\ ${ }^{1}$ Department of Parasitology and Invasive Diseases, ${ }^{2}$ Department of Swine Diseases, \\ National Veterinary Research Institute, 24-100 Pulawy, Poland \\ maciej.kochanowski@piwet.pulawy.pl
}

Received: June 16, $2017 \quad$ Accepted: November 2, 2017

\begin{abstract}
Introduction: The aim of study was to estimate the prevalence and intensity of intestinal parasite infections in pigs in Poland and evaluate the influence of factors related to the production system on the infection intensity. Material and Methods: A total of 70 pig farms of all Polish provinces, differing in the herd size and production system, were selected for the study. Fresh faecal samples were collected from all age groups: suckling piglets, weaners, fatteners, and lactating sows. Moreover, data were obtained regarding the size of the herd, the use of paddock and all-in/all-out system, the presence of diarrhoea, and the type of flooring. Results: Parasite eggs or oocysts were detected in 57 of the 70 examined pig farms. Oesphagostomum spp. eggs were found in the largest number of farms (68.6\%). Moreover, coccidia (42.9\%), Ascaris suum (28.6\%), Trichuris suis (21.4\%), and Strongyloides spp. (11.4\%) were detected. The highest prevalence of coccidia and Strongyloides spp. was found in suckling piglets, A. suum and T. suis in fatteners, and Oesphagostomum spp. in sows. Higher prevalence of parasites was detected in small farms than in medium and large farms, except the prevalence of coccidia, which was the highest in medium farms. Simultaneous infection with several parasites was more often detected than with one parasite. Odds ratio of parasites occurrence was higher in farms with paddock and litter floor and in farms which do not use all-in/all-out system. Conclusion: Relatively high prevalence of intestinal parasites was found in pigs in Poland. Moreover, specific distribution of parasites in different age groups and farms of different size was observed. Influence of breeding factors on parasite prevalence was identified.
\end{abstract}

Keywords: pigs, intestinal parasites, production system, Poland.

\section{Introduction}

Intestinal parasites have a significant impact on the efficiency of pig production. Parasitic infections of young animals are especially dangerous, because they can cause diarrhoea and dehydration that could lead to death of the animals. Parasites can also worsen the weight gain of pigs, causing economic losses (20). It was estimated that the infection with pig parasites reduces the feed intake by about $50 \mathrm{~g}$, which leads to delay in achieving the slaughter weight by 10-15 days (33). Moreover, the infection can cause intestinal malabsorption, impaired fertility, delayed or incomplete immunity after vaccination, and worse meat quality (15). In spite of a significant effect on the functioning of the host organism, the clinical symptoms of intestinal parasitic infection are not specific. Thus, diagnosis of the infection should be based on laboratory examinations.

Pig production in Poland is relatively large - the number of pigs in June 2016 was 10,239.4 thousands (according to the Report of Central Statistical Office of Poland, 2016). Poland is the fourth largest producer of pork and sixth in terms of pig production in the European Union (Eurostat, 2015). Pig meat market is one of the main sectors of agribusiness in Poland, and the supply and consumption of pork are the highest among all kinds of meat (35). Despite the importance of pig production in Poland, parasitological studies on pigs are insufficient - only a few investigations were conducted, and most of them were carried out on a small number of samples $(1,10,23,25,26)$.

Another important reason for parasitological testing of pigs is monitoring the presence of zoonotic 
parasites, such as Ascaris suum or Trichuris suis, especially because of the agricultural use of pig faeces as fertiliser. According to the regulations in Poland, organic and organic-mineral fertilisers and soil conditioners cannot contain viable eggs of Ascaris spp., Trichuris spp., and Toxocara spp. (28). However, in the case of natural fertilisers such as pig manure, parasitological examination is not obligatory.

Many factors can affect the prevalence and intensity of parasitic infection. Particularly important are factors relating to the breeding system: herd size, type of flooring, use of all-in/all-out system, or use of paddock. In Poland, there are different pig production systems. Despite the trend of concentration of pig husbandry, swine production is still characterised by a fragmented structure (37). Therefore, information about factors affecting the varied production systems is essential for farm functioning.

The aim of the study was to estimate the prevalence and intensity of intestinal parasite infections in pigs in Poland and evaluate the influence of factors related to the production system on the infection intensity.

\section{Material and Methods}

Pig farms. Seventy pig farms from all Polish provinces were selected for the study (Fig. 1). The farms differed in herd size: small farms (1-50 sows in the basic herd; 27 farms; 379 samples), medium farms
(51-500 sows; 37 farms; 628 samples), and large farms (more than 500 sows; 6 farms; 112 samples). There were also some differences in production systems. Information about farms was obtained using a questionnaire. Data about herd size, use of paddock, use of all-in/all-out system, presence of diarrhoea, and the type of flooring (litter or non-litter) are presented in Table 1.

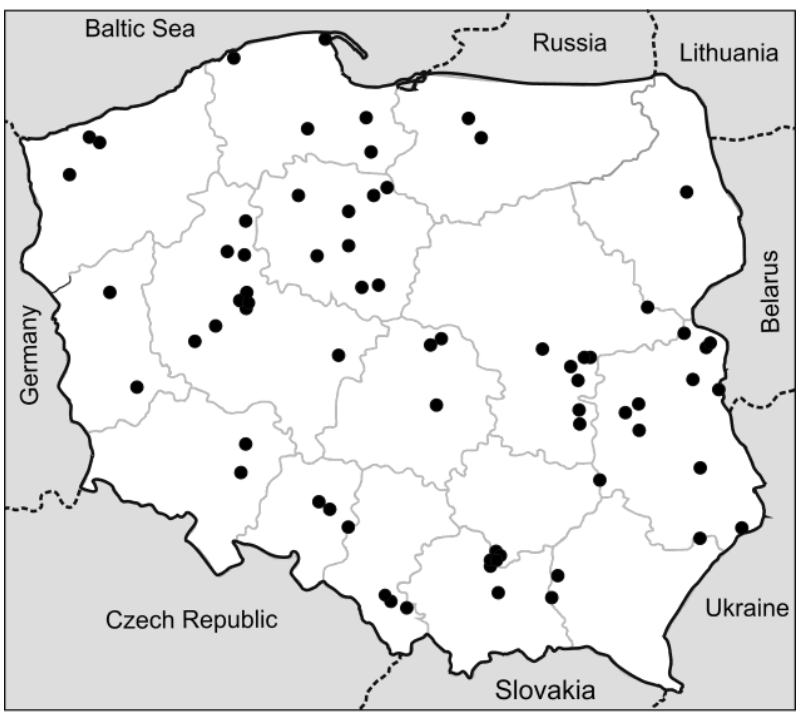

- pig farm

Fig. 1. Distribution of pig farms under investigation

Table 1. Influence of factors associated with breeding on the presence of parasites

\begin{tabular}{|c|c|c|c|c|c|c|c|c|c|c|c|c|}
\hline \multirow{2}{*}{\multicolumn{2}{|c|}{ Factor }} & & \multicolumn{2}{|c|}{ Coccidia } & \multicolumn{2}{|c|}{ Strongyloides } & \multicolumn{2}{|c|}{ Ascaris } & \multicolumn{2}{|c|}{ Trichuris } & \multicolumn{2}{|c|}{ Oesophagostomum } \\
\hline & & $\mathrm{n}$ & $\begin{array}{c}\% \text { farm } \\
(95 \% \\
\text { CI })\end{array}$ & $\begin{array}{c}\text { OR } \\
(95 \% \\
\text { CI })\end{array}$ & $\begin{array}{c}\% \text { farm } \\
(95 \% \\
\text { CI })\end{array}$ & $\begin{array}{c}\text { OR } \\
(95 \% \\
\text { CI })\end{array}$ & $\begin{array}{c}\% \text { farm } \\
(95 \% \\
\mathrm{CI})\end{array}$ & $\begin{array}{c}\text { OR } \\
(95 \% \\
\text { CI })\end{array}$ & $\begin{array}{c}\% \text { farm } \\
(95 \% \\
\mathrm{CI})\end{array}$ & $\begin{array}{c}\text { OR } \\
(95 \% \\
\text { CI })\end{array}$ & $\begin{array}{c}\% \text { farm } \\
(95 \% \\
\mathrm{CI})\end{array}$ & $\begin{array}{c}\text { OR } \\
(95 \% \\
\mathrm{CI})\end{array}$ \\
\hline \multirow[b]{2}{*}{$\begin{array}{l}\frac{y}{0} \\
0 \\
\frac{0}{0} \\
\text { ¿ }\end{array}$} & + & 6 & $\begin{array}{c}33.3 \\
(9.7-70.0) \\
\end{array}$ & $\begin{array}{c}0.6 \\
(0.1-3.8)\end{array}$ & $\begin{array}{c}33.3 \\
(9.7-70.0) \\
\end{array}$ & $\begin{array}{c}4.8 \\
(0.7-32.1) \\
\end{array}$ & $\begin{array}{c}33.3 \\
(9.7-70.0) \\
\end{array}$ & $\begin{array}{c}1.3 \\
(0.2-7.6)\end{array}$ & $\begin{array}{c}33.3 \\
(9.7-70.0) \\
\end{array}$ & $\begin{array}{c}2.0 \\
(0.3-11.9)\end{array}$ & $\begin{array}{c}100.0 \\
(61.0-100.0)\end{array}$ & $\begin{array}{c}6.9 \\
(0.4-127.8) \\
\end{array}$ \\
\hline & - & 64 & $\begin{array}{c}43.8 \\
(32.3-55.9) \\
\end{array}$ & & $\begin{array}{c}9.4 \\
(4.4-19.0) \\
\end{array}$ & & $\begin{array}{c}28.1 \\
(18.6-40.1) \\
\end{array}$ & & $\begin{array}{c}20.3 \\
(12.3-31.7)\end{array}$ & & $\begin{array}{c}65.6 \\
(53.4-76.1)\end{array}$ & \\
\hline \multirow{2}{*}{ 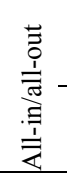 } & + & 30 & $\begin{array}{c}36.7 \\
(21.9-54.5)\end{array}$ & $\begin{array}{c}0.6 \\
(0.2-1.7)\end{array}$ & $\begin{array}{c}6.7 \\
(1.8-21.3)\end{array}$ & $\begin{array}{c}0.4 \\
(0.1-2.2)\end{array}$ & $\begin{array}{c}26.7 \\
(14.2-44.4)\end{array}$ & $\begin{array}{c}0.8 \\
(0.3-2.4)\end{array}$ & $\begin{array}{c}16.7 \\
(7.3-33.6)\end{array}$ & $\begin{array}{c}0.6 \\
(0.2-2.0)\end{array}$ & $\begin{array}{c}66.7 \\
(48.8-80.8)\end{array}$ & $\begin{array}{c}0.9 \\
(0.3-2.4)\end{array}$ \\
\hline & - & 40 & $\begin{array}{c}47.5 \\
(32.9-62.5) \\
\end{array}$ & & $\begin{array}{c}15.0 \\
(7.1-29.1)\end{array}$ & & $\begin{array}{c}30.0 \\
(18.1-45.4)\end{array}$ & & $\begin{array}{c}25.0 \\
(14.2-40.2)\end{array}$ & & $\begin{array}{c}70.0 \\
(54.6-81.9)\end{array}$ & \\
\hline \multirow{2}{*}{ 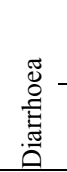 } & + & 52 & $\begin{array}{c}42.3 \\
(29.9-55.8) \\
\end{array}$ & $\begin{array}{c}0.9 \\
(0.3-2.7) \\
\end{array}$ & $\begin{array}{c}11.5 \\
(5.4-23.0) \\
\end{array}$ & $\begin{array}{c}1.0 \\
(0.2-5.7) \\
\end{array}$ & $\begin{array}{c}21.2^{\mathrm{A}}(12.2- \\
34.0)\end{array}$ & $\begin{array}{c}0.3 \\
(0.1-0.8) \\
\end{array}$ & $\begin{array}{c}19.2 \\
(10.8-31.9) \\
\end{array}$ & $\begin{array}{c}0.6 \\
(0.2-2.1) \\
\end{array}$ & $\begin{array}{c}69.2 \\
(55.7-80.1) \\
\end{array}$ & $\begin{array}{c}1.1 \\
(0.4-3.5) \\
\end{array}$ \\
\hline & - & 18 & $\begin{array}{c}44.4 \\
(24.6-66.3)\end{array}$ & & $\begin{array}{c}11.1(3.1- \\
32.8)\end{array}$ & & $\begin{array}{c}50.0^{\mathrm{B}} \\
(29.0-71.0)\end{array}$ & & $\begin{array}{c}27.8 \\
(12.5-50.9)\end{array}$ & & $\begin{array}{c}66.7 \\
(43.7-83.7) \\
\end{array}$ & \\
\hline \multirow{2}{*}{ 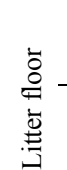 } & + & 43 & $\begin{array}{c}46.5 \\
(32.5-61.1)\end{array}$ & $\begin{array}{c}1.5 \\
(0.6-4.0)\end{array}$ & $\begin{array}{c}18.6^{\mathrm{A}} \\
(9.7-32.6) \\
\end{array}$ & $\begin{array}{c}13.2 \\
(0.7-238.2) \\
\end{array}$ & $\begin{array}{c}27.9 \\
(16.7-42.7)\end{array}$ & $\begin{array}{c}0.9 \\
(0.3-2.7)\end{array}$ & $\begin{array}{c}23.3 \\
(13.2-37.7)\end{array}$ & $\begin{array}{c}1.3 \\
(0.4-4.4)\end{array}$ & $\begin{array}{c}72.1 \\
(57.3-83.3) \\
\end{array}$ & $\begin{array}{c}1.5 \\
(0.5-4.2)\end{array}$ \\
\hline & - & 27 & $\begin{array}{c}37.0 \\
(21.5-55.8) \\
\end{array}$ & & $0^{\mathrm{B}}$ & & $\begin{array}{c}29.6 \\
(15.9-48.5) \\
\end{array}$ & & $\begin{array}{c}18.5 \\
(8.2-36.7) \\
\end{array}$ & & $\begin{array}{c}63.0 \\
(44.2-78.5) \\
\end{array}$ & \\
\hline
\end{tabular}

$(+)$ presence or $(-)$ absence of factor; $n$ - the number of farms; $\%$ farm - the percentage of farms with occurrence of parasites; $95 \%$ CI - 95\% confidence interval; OR - odds ratio of parasites occurrence on farm with present breeding factor; A B - the percentage of farms grouped by factors and statistically significantly different $(\mathrm{P}<0.05)$ 
Faecal samples. Fresh faecal samples were collected from the following age groups: suckling piglets, weaners, fatteners, and lactating sows. Seven to twenty-three samples were collected from each farm, depending on the herd size. Faecal samples of suckling piglets (7 to 28-day-old) were collected directly from the rectum. Samples were taken from three-five piglets per litter and pooled. Samples from other animal groups were collected from the ground, immediately after defecation. In total, 1,119 samples were collected: 170 from weaners, 215 from fatteners, 367 from suckling piglets, and 367 from lactating sow. After collection the samples were stored at $4^{\circ} \mathrm{C}$ until further analyses.

Methods. The samples were tested by McMaster method with modification by Raynaud (27). Parasite eggs and oocysts were identified based on their morphology and size (34). The number of parasite eggs and oocysts per $1 \mathrm{~g}$ of faeces (EPG/OPG) was calculated according to the McMaster method.

Statistical analysis. Statistical analysis was performed using IBM SPSS Statistics 22, Microsoft Excel 2010, EpiTools epidemiological calculators (32) and QPweb (29). Distribution of quantitative variables was tested by Shapiro-Wilk test and normality hypothesis of the data was rejected. The prevalence was calculated as the number of pigs in which parasite eggs or oocysts were detected divided by the total number of pigs in a group. Prevalence was calculated in percentage. Also, total prevalence of samples and farms was calculated as the number of samples/farms in which at least one parasite was detected, divided by the total number of samples/farms. The intensity of infection was calculated as the number of parasite eggs or oocysts divided by the number of parasite positive pigs/litter. Also, 95\%Wilson score confidence intervals $(95 \% \mathrm{CI})$ of prevalence and bootstrap 95\% CI (using 1,000 replicates) of intensity of infection were calculated. Differences between dichotomous variable (prevalence) were estimated by chi-square test with Bonferroni correction for multiple comparisons. Differences between multiple groups of quantitative variables (intensity of infection) were determined by the Kruskal-Wallis test with Bonferroni correction, and U Mann-Whitney test was used for inter-group differences. Odds ratio (OR) with $95 \% \mathrm{CI}$ and the percentage of positive farms for each breeding factor were also calculated. Phi correlation coefficient between prevalences of different types of parasites and Spearman correlation coefficient (rho) between intensities of infection with all detected parasite types were calculated. Moreover, phi correlation coefficient between prevalences as well rho correlation coefficient between intensities of infection in the groups of suckling piglets and lactating sows were calculated. Differences were considered to be statistically significant at $\mathrm{P}<0.05$.

\section{Results}

Prevalence and intensity of parasites. The results concerning prevalence and intensity are shown in Table 2. Among all tested samples $(n=1,119)$ the highest prevalence of Oesophagostomum spp. was found. Prevalence of coccidia, A. suum, T. suis, and Strongyloides spp. was lower. Statistically significant differences were found between the occurrence of Oesophagostomum spp. and other types of parasites, and among coccidia with other parasites. In 57/70 pig farms parasite eggs or oocysts were detected. The number of positive farms with Oesophagostomum spp. eggs was statistically significantly higher than the number of farms with other parasites. Moreover, statistically significant differences between the number of farms with coccidian oocysts and farms with $T$. suis and Strongyloides spp. were found.

Table 2. Prevalence of parasites and infection intensity detected in samples and farms

\begin{tabular}{|c|c|c|}
\hline & $\begin{array}{l}\text { Positive samples }(\%) \\
(95 \% \mathrm{CI}) \\
\text { EPG }(95 \% \mathrm{CI})\end{array}$ & $\begin{array}{l}\text { Positive farms (\%) } \\
(95 \% \text { CI })\end{array}$ \\
\hline Oesophagostomum & $\begin{array}{l}24.2(21.8-26.8)^{\mathrm{A}} \\
1,040.9 \mathrm{EPG} \\
(773-1,520)\end{array}$ & $68.6(57.0-78.2)^{\mathrm{A}}$ \\
\hline Coccidia & $\begin{array}{l}7.9(6.4-9.6)^{\mathrm{B}} \\
4,642.5 \mathrm{OPG} \\
(2,440-1,520)\end{array}$ & $42.9(31.9-54.5)^{\mathrm{B}}$ \\
\hline Ascaris & $\begin{array}{l}3.5(2.6-4.7)^{\mathrm{C}} \\
761.69 \mathrm{EPG} \\
(374-1,810)\end{array}$ & $28.6(19.3-40.1)^{\mathrm{B}, \mathrm{C}}$ \\
\hline Trichuris & $\begin{array}{l}2.1(1.4-3.1)^{\mathrm{C}} \\
126.48 \mathrm{EPG} \\
(32.8-485)\end{array}$ & $21.4(13.4-32.4)^{\mathrm{C}}$ \\
\hline Strongyloides & $\begin{array}{l}2.0(1.3-3.0)^{\mathrm{C}} \\
1,326.8 \mathrm{EPG} \\
(492-3,180)\end{array}$ & $11.4(5.9-21.0)^{\mathrm{C}}$ \\
\hline Total & $39.4(39.4-36.6)$ & $81.4(70.8-88.8)$ \\
\hline
\end{tabular}

95\% CI - 95\% confidence interval; EPG - eggs per gram of faeces; OPG - oocysts per gram of faeces; values in the same column with differing superscripts $\left({ }^{A}, \mathrm{~B}, \mathrm{C}\right)$ are significantly different $(\mathrm{P}<0.05)$

Parasites in different age groups. The results concerning parasitic prevalence and intensity in different age groups are presented in Fig. 2. The highest percentage of coccidian positive farms and samples were found in suckling piglets $(31.4 \%$ of the farms; $14.2 \%$ of the samples), lower in sows $(17.1 \%$ of the farms; $6.0 \%$ of the samples), fatteners $(8.6 \%$ of the farms; $3.7 \%$ of the samples), and the lowest in weaners (7.1\% the farms; $3.5 \%$ of the samples). Statistically significant differences in the coccidian prevalence were found between the group of suckling piglets and the groups of weaners, fatteners, and sows. Oesophagostomum spp. prevalence was the highest in sows $(60.0 \%$ of the farms; $51.8 \%$ of the samples). Lower prevalence was noted in suckling piglets $(35.7 \%$ of the farms; $13.1 \%$ of the samples) and fatteners 
( $28.6 \%$ of farms; $18.1 \%$ of the samples), and the lowest in weaners $(12.9 \%$ of the farms; $12.9 \%$ of the samples). Statistically significant differences in Oesophagostomum spp. prevalence were found between the group of sows and the groups of weaners, suckling piglets and fatteners. Moreover, statistically significant differences were observed regarding the prevalence of Oesophagotomum spp. between the groups of suckling piglets and weaners. A. suum prevalence was the highest in fatteners $(15.7 \%$ of farms; $6.5 \%$ of the samples) and slightly lower in sows (14.3\% of the farms; $3.8 \%$ of the samples). Lower A. suum prevalence was found in suckling piglets (7.1\% of the farms; $0.5 \%$ of the samples) and weaners ( $2.9 \%$ of the farms; $1.2 \%$ of the samples). Statistically significant differences in $A$. suum prevalence were found between weaners and fatteners. Also, statistically significant differences in $A$. suum prevalence between the group of suckling piglets and the groups of fatteners and sows were found. The highest prevalence of $T$. suis was observed in sows $(10.0 \%$ of the farms; $3.0 \%$ of the samples). Lower prevalence was found in fatteners (4.3\% of the farms; $1.4 \%$ of the samples), suckling piglets $(2.9 \%$ of the farms; of $0.5 \%$ of the samples) and weaners $(2.9 \%$ of the farms; $1.2 \%$ of the samples $)$. In the case of Strongyloides spp., the highest prevalence was observed in suckling piglets $(11.4 \%$ of the farms; $3.3 \%$ of the samples), lower in sows $(4.3 \%$ of the farms; $2.5 \%$ of the samples) and weaners $(2.9 \%$ of the farms; $1.8 \%$ of the samples). In the fatteners Strongyloides was not detected. Statistically significant differences in Strongyloides prevalence were observed between fatteners and suckling piglets.

Among all age groups, the highest intensity of coccidian infection was found in suckling piglets (9,378.6 OPG). Lower number of these protozoa was found in sows $(4,398.0$ OPG) and fatteners (723.8 OPG) and the lowest in weaners (153.3 OPG). Statistically significant differences were found between suckling piglets and sows and fatteners. Moreover, the highest intensity of infection with Oesophagostomum spp. was observed in suckling piglets $(1,424.5$ EPG), whereas intensity was found in sows (957.7 EPG), fatteners (266.9 EPG), and weaners (147.0 EPG). Statistically significant differences in intensities of infections with Oesophagostomum spp. were found between suckling piglets and sows, and between sows and weaners. In the case of $A$. suum, the highest intensity of infection was observed in fatteners $(1,411.0$ EPG), lower in sows (550.5 EPG) and weaners (233.3 EPG), and the lowest in suckling piglets (113.6 EPG). The highest intensity of infection with $T$. suis was found in sows (219.7 EPG) and lower in fatteners (53.3 EPG), suckling piglets (52.5 EPG), and weaners (32.5 EPG). The highest EPG of Strongyloides spp. was found in sows $(2,418.6 \mathrm{EPG})$ and lower in suckling piglets (867.9 EPG) and weaners (500.0 EPG). No infection with Strongyloides spp. was found in the fatteners.
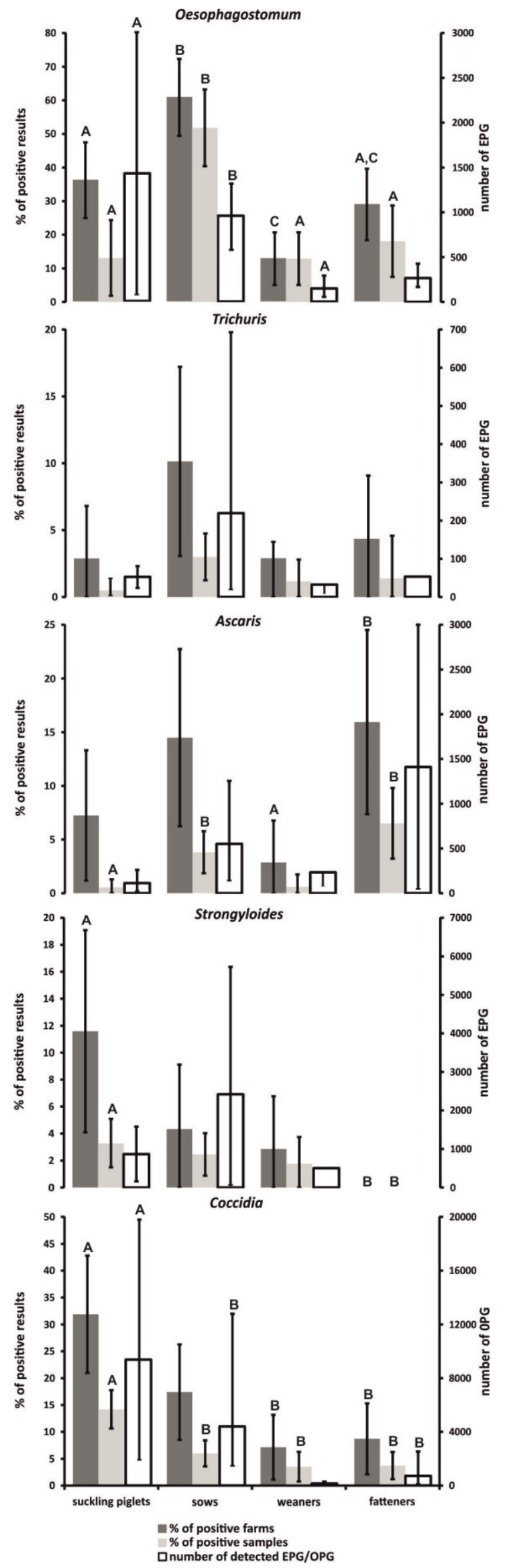

Fig. 2. Prevalence and intensity of parasitic infection in all age groups of pigs. Error bars represent $95 \%$ confidence interval. Groups identified by different superscripts (A, B, C ) between the bars with the same colour are significantly different $(\mathrm{P}<0.05)$ 
Parasites in farms of different size. The results concerning parasitic prevalence in farms of different size are presented on Fig. 3. The highest prevalence of parasites was found mostly in samples from small farms and the lowest in the large farms. Although Oesophagostomum spp. infection was frequently found in all types of farms (about $70 \%$ ), the number of Oesophagostomum positive samples was statistically significantly lower in large farms than in other types. The prevalence of coccidia was also high in mediumsize $(51.4 \%$ of the farms; $7.5 \%$ of the samples) and small-size farms $(40.7 \%$ of the farms; $10.8 \%$ of the samples). No coccidian infection was detected in large farms. Furthermore, statistically significant differences in coccidian prevalence were found between large farms and small and medium farms. A. suum infection was the most frequent in small farms $37.0 \%$ of the farms; $6.6 \%$ of the samples), and $A$. suum eggs were slightly less often detected in medium farms $(21.6 \%$ of the farms; $2.5 \%$ of the samples) and large farms (33.3\% of the farms; $1.8 \%$ of the samples). Statistically significant differences in A. suum prevalence were found in samples from medium and small farms. T. suis eggs were the most frequently detected in samples from small farms $(25.9 \%$ of the farms; $1.9 \%$ of the samples) and less often in medium farms $(19.4 \%$ of the farms; $1.6 \%$ of the samples). In samples from large farms, T. suis eggs were not detected. Moreover, Strongyloides spp. eggs were found only in samples from small farms ( $18.5 \%$ of the farms; $2.4 \%$ of the samples) and medium farms ( $8.1 \%$ of the farms; $1.4 \%$ of the samples).

The highest intensity of coccidian infection was found in medium farms (6,981.3 OPG) and lower in small farms $(5,153.5$ OPG). Also, statistically significant differences in intensity of coccidian infections were found between medium and small farms. The highest EPG value of Oesophagostomum spp. was noted in small farms (1,059.2 EPG), lower in medium (462.0 EPG) and large farms (39.4 EPG). Statistically significant differences in intensity of infections with Oesophagostomum spp. were found among small, medium, and large farms. The highest intensity of $A$. suum infection was found in mediumsize farms (1,103.8 EPG) and lower in small (508.1 EPG) and large farms (82.5 EPG). The highest intensity of $T$. suis infection was observed in medium-size farms (74.5 EPG). T. suis infection was lower in small farms (52.5 EPG). In the large farms, T. suis infection was not detected. The highest infection with Strongyloides spp. was found in medium-size farms (2,876.0 EPG). Much lower intensity of Strongyloides spp. infection was found in small farms (246.6 EPG) and in large farms it was not detected.

Correlations between parasite groups. Low correlations (range of phi from -0.259 to 0.585 ) were found between the prevalence of detected parasite types. Independently, the correlations between prevalence and intensity of parasite infection of sows and their suckling piglets were analysed.
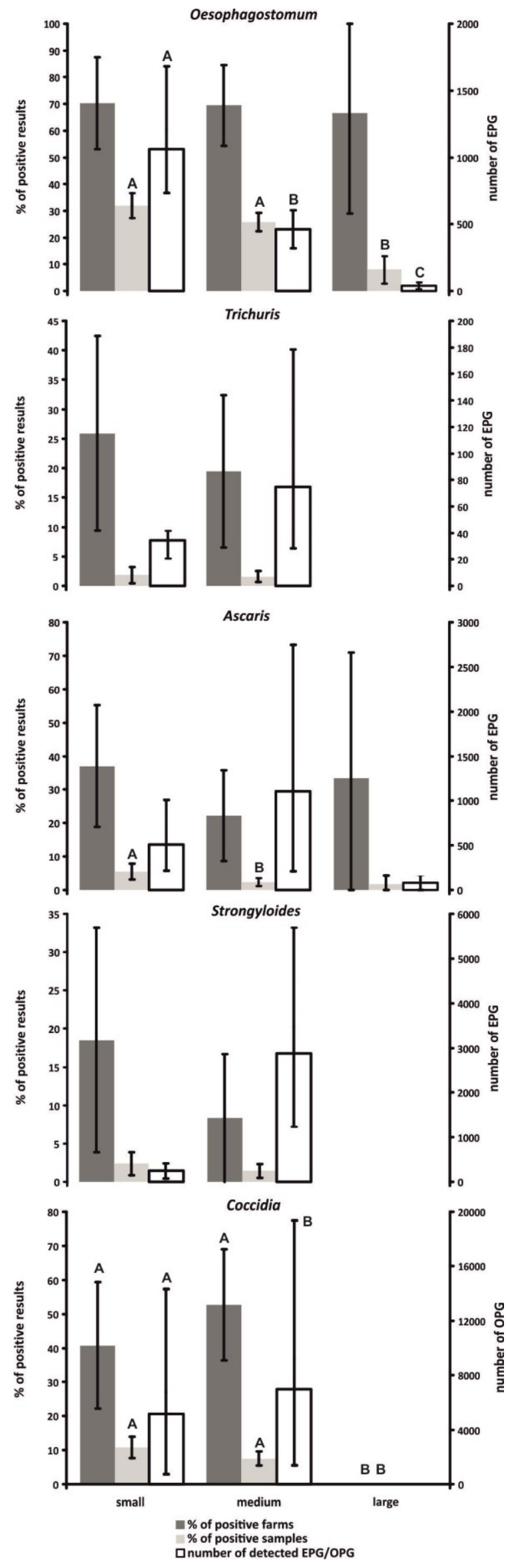

Fig. 3. Prevalence and intensity of parasitic infection in farms of different size. Error bars represent $95 \%$ confidence interval. Groups identified by different superscripts $(\mathrm{A}, \mathrm{B}, \mathrm{C})$ between the bars with the same colour are significantly different $(\mathrm{P}<0.05)$ 
A weak correlation between sows and suckling piglets in Oesophagostomum spp. prevalence was found ( $\mathrm{phi}=0.243$ ), but no similar correlations were found between suckling piglets and sows for other types of parasites. Moreover, all correlations of intensity of infection between sows and suckling piglets were low (range of Spearman's rho from 0.198 to 0.526 ), with the exception of coccidia and $T$. suis where no correlation was observed.

Mono- and multiparasitism. In 17 farms only one type of parasite was found. In these farms, Oesophagostomum spp. occurred most often (11 farms), coccidia were observed less frequently (five farms), and $A$. suum eggs were found in one farm only. Coexistence of parasites was observed in 40 farms. It usually involved two types of parasite (23 farms). Simultaneous occurrence of several parasites was less frequent: 3 parasites in 12 farms, 4 parasites in 3 farms, and 5 parasites in 2 farms. The results are presented in Table 3.

Table 3. Distribution of single or multiple types of intestinal pig parasites

\begin{tabular}{llll}
\hline Number of parasites & parasites & frequency & \% of farms \\
\hline Lack of parasites & - & 13 & 18.6 \\
\hline \multirow{4}{*}{1} & $\mathrm{O}$ & 11 & 15.7 \\
& $\mathrm{~K}$ & 5 & 7.1 \\
& $\mathrm{~A}$ & 1 & 1.4 \\
\hline \multirow{4}{*}{2} & $\mathrm{O}+\mathrm{K}$ & 13 & 18.6 \\
& $\mathrm{O}+\mathrm{A}$ & 5 & 7.1 \\
& $\mathrm{O}+\mathrm{S}$ & 2 & 2.9 \\
& $\mathrm{O}+\mathrm{T}$ & 1 & 1.4 \\
& $\mathrm{~K}+\mathrm{A}$ & 1 & 1.4 \\
& $\mathrm{~A}+\mathrm{S}$ & 1 & 1.4 \\
\hline \multirow{4}{*}{3} & $\mathrm{~K}+\mathrm{O}+\mathrm{A}$ & 2 & 2.9 \\
& $\mathrm{~K}+\mathrm{O}+\mathrm{T}$ & 3 & 4.3 \\
& $\mathrm{O}+\mathrm{A}+\mathrm{T}$ & 5 & 7.1 \\
& $\mathrm{O}+\mathrm{T}+\mathrm{S}$ & 1 & 1.4 \\
4 & $\mathrm{~K}+\mathrm{A}+\mathrm{T}$ & 1 & 1.4 \\
\hline \multirow{4}{*}{5 (all parasites) } & $\mathrm{K}+\mathrm{O}+\mathrm{T}+\mathrm{S}$ & 1 & 1.4 \\
& $\mathrm{~K}+\mathrm{O}+\mathrm{A}+\mathrm{T}$ & 1 & 1.4 \\
& $\mathrm{~K}+\mathrm{O}+\mathrm{A}+\mathrm{S}$ & 1 & 1.4 \\
\hline
\end{tabular}

$\mathrm{O}$ - Oesophagostomum, $\mathrm{K}$ - coccidia, A - Ascaris, T - Trichuris, $\mathrm{S}$ - Strongyloides

Risk factors of parasitic infection associated with breeding system. Table 1 shows the relationship between parasite infection and breeding system. There is a higher chance of occurrence of Strongyloides spp., Oesphagostomum spp., and T. suis in farms with paddock. Lack of all-in/all-out system was associated with a slightly higher probability of occurrence of Strongyloides spp., A. suum, T. suis, Oesophagostomum spp., and coccidia. Furthermore, relatively high OR values indicated a higher likelihood of occurrence of coccidia, Strongyloides spp., and Oesophagostomum spp. in farms with litter flooring.

Moreover, the comparison conducted by chisquare test showed that Strongyloides spp. occurred significantly more frequently in farms with litter than in non-litter farms. Also, A. suum infection occurred significantly more often in diarrhoea-free farms than in farms where diarrhoea was observed in pigs.

\section{Discussion}

Five types of parasites: coccidia, Strongyloides spp., A. suum, T. suis, and Oesophagostomum spp. were found in tested pig faeces samples. The same pig parasites were found in Poland by Bartosik et al. (1). Most of these parasites were also detected in farms in Germany, the Netherlands, China, Japan, or the Nordic countries $(6,8,11,16,17,30)$. Our study shows that the infection with intestinal parasites is quite frequent, and affects more than $81 \%$ of pig farms in Poland. Such frequent occurrence of pig parasites, especially Oesophagostomum spp., coccidian, and A. suum, could cause economic losses in farms. However, the low prevalence of Strongyloides spp. and T. suum (about 2\%) may suggest that these parasites have no significant impact on production. Additionally, the occurrence of Strongyloides spp. and T. suis is characteristic for pigs breeding in the traditional manner under poor zoohygienic conditions (21).

The results of a recent study by Popiołek et al. (26) on intestinal parasites of pigs in Poland differ from ours. Their results indicate the highest prevalence of $T$. suis, less frequent of A. suum and Oesophagostomum spp., and the least frequent of $S$. ransomi. Probably the reason for the differences was the significantly smaller number of samples they investigated, collected from two farms only. Therefore, it is hard to compare these results with the results of our investigation. On the other hand, the results of studies conducted on a larger number of samples are similar to ours, and show the highest prevalence of Oesophagostomum spp. $(1,22)$. Karamon et al. (12) found high prevalence of Eimeria spp. and Isospora suis -11.5 and $66.7 \%$, respectively, in suckling piglets and sows. In the presented study the prevalence of coccidia decreased to about $29 \%$, which could indicate an improvement of zoohygienic conditions over the last 10 years in pig farms in Poland.

The distribution of parasite prevalence is characteristic for each age group. The highest prevalence of coccidia and Strongyloides spp. was found in suckling piglets, A. suum and T. suis in fatteners, and Oesphagostomum spp. in sows. A similar distribution of parasites in pigs was observed in the Nordic countries (30). The differences in parasite prevalence distribution are probably connected with different immunogenic properties of various parasites (30). Since Oesophagostomum spp. infection causes weak stimulation of pig immune system, prevalence of this parasite increases with age, while $A$. suum infection is characteristic for the young growing pigs (19). According to Weng et al. (38), lactating sows are the main reservoir of infection for other pig groups, and therefore sows should be particularly parasitologically 
examined. Especially A. suum, Oesophagostomum spp., and Strongyloides spp. can cross the placenta (21). In our study, statistically significant correlations were found between sows and piglets regarding the prevalence of Oesophagostomum spp. and infection intensity of Oesophagostomum spp., A. suum and Strongyloides spp.

It should be noted that A. suum, T. suis, and Oesophagostomum spp. eggs were found in faeces of suckling piglets. Detection of these parasites, which have quite a long prepatent period, is probably due to the passive passage of eggs, ingested from the environment through the piglet gastrointestinal tract. Therefore, the presence of parasite eggs in the faeces is not always indicative of parasitic infection. Moreover, Nosal et al. (23) confirmed in post-mortem examination false positive coproscopic results for the presence of $A$. suum in the piglets and fatteners faeces. Similar false positive results of Trichuris infection may be caused by T. muris eggs transferred from mice faeces (21).

It was demonstrated that factors of breeding system can influence the parasite prevalence and the intensity of infection. Herd size is also an important factor. The highest detection of parasites occurs mostly in small farms and this is probably associated with poor zoohygienic conditions in comparison to medium- and large-size farms. In particular, large farms usually have a well-organised biosecurity system (4). Fudalewicz and Novosad (7) found that parasite prevalence in small pig farms in southern Poland was even up to $99.7 \%$. Nosal and Eckert (22) also found higher prevalence in small and lower in large pig farms in Poland.

Another important factor is the type of flooring in pens. The use of non-litter flooring in farm is associated with a lower prevalence of parasites because it provides better hygienic conditions (11). Contrastingly, the use of deep litter facilitates the contact with animal faeces, which causes a higher risk of parasitic infection in the herd $(1,36)$. In the case of Strongyloides spp., free-living larvae require humid environment to develop; litter can provide these conditions. Our study also confirmed statistically significantly higher prevalence of Strongyloides spp. in farms using litter.

The use of all-in/all-out production system allows to reduce the occurrence of parasite in farms. The results of this study showed that in farms where this system was not used, parasite prevalence was higher. A higher prevalence of parasites was demonstrated in most farms with paddock. Because disinfection of paddock is difficult, parasite eggs can accumulate and increase the risk of infection (18). Roepstroff et al. (31) confirmed the long-term circulation of A. suum eggs in pig farms with paddock. Moreover, infective L3 larvae of Oesophagostomum can survive in outdoor conditions for about a year (21), whereas $T$. suis eggs can be invasive up to 11 years (2).

The study did not find any relationship between the occurrence of parasites and diarrhoea in farms. However, eggs of A. suum were found more often in farms where no diarrhoea was observed. This suggests that the diarrhoea was caused by factors other than intestinal parasites, such as perhaps Lawsonia intracellularis, Brachyspira hyodysenteriae, or Salmonella spp. (5). Moreover, parasite infection, in particular with low intensity, may not show any clinical signs except worse weight gain.

It is worth noting that most cases of parasite infections were caused by coexistence of several types of parasites. In the largest number of farms, simultaneous occurrence of Oesophagostomum spp. and coccidia was found. Moreover, our study showed that all correlations between parasites were weak and positive, except the negative correlation between coccidia and Oesophagostomum spp. Weng et al. (38) also found common simultaneous presence of a few types of parasites. In Japan, parasitic infection was usually caused by Eimeria spp. together with other parasites (17). Coexistent parasites may have an influence on each other. Antagonistic effect of $A$. suum and $O$. dentatum (9), and T. suis and O. dentatum (24) was found in pigs. These interactions may result from the direct impact of parasites on each other or the host's immune response to infection.

Zoonotic intestinal parasites of pigs are dangerous not only for farm workers, but also people living in contaminated environment, especially when pigs faeces are used as manure or to produce organic fertilisers, organic-mineral fertilisers, and soil conditioners. Parasite eggs of pigs can also be found in sewage sludge from which fertilisers are produced $(3,39)$. Eggs of parasites were found in about $45 \%$ of the sludge samples in Poland (14). Moreover, in the soil samples collected from vegetable farms in south-eastern Poland a high percentage of Ascaris and Trichuris eggs (from about $30 \%$ to $80 \%$ ) were found (13). This demonstrates frequent occurrence of Ascaris and Trichuris eggs in agricultural environment.

Currently in Poland, as in most European countries, pig breeding is conducted in large industrial farms. In these farms, the prevalence and intensity of parasite infection are generally low due to the good zoohygienic conditions. Nevertheless, the total elimination of parasitic infection is difficult to obtain. On the other hand, organic farms are currently growing in popularity in the world. According to available studies, pigs held in organic farms are more exposed to parasite infection, owing to the inability to maintain proper hygienic conditions comparable to conventional farms (6). In addition, the import of new animal species may entail the appearance of, new parasites which have not yet occurred in this area of Europe, e.g. Oesophagostomum quadrispinulatum. Therefore parasitological examination of the herd continues to be important.

Conflict of Interests Statement: The authors declare that there is no conflict of interests regarding the publication of this article. 
Financial Disclosure Statement: This study was supported by the National Science Centre (Poland), Grant No. N N308 571740.

\section{Animal Rights Statement: None required.}

\section{References}

1. Bartosik J., Rekiel A., Klockiewicz M., Górski P., Batorska M.: The effect of housing system on the incidence of intestinal parasite infestation in pigs. JCEA 2012, 13, 760-768.

2. Burden D.J., Ginnivan M.J.: The destruction of pig helminth ova and larvae in a slurry treatment process. Vet Rec 1978, 103, 373-375.

3. Dąbrowska J., Zdybel J., Karamon J., Kochanowski M., Stojecki K., Cencek T., Kłapeć T.: Assessment of viability of the nematode eggs (Ascaris, Toxocara, Trichuris) in sewage sludge with the use of LIVE/DEAD Bacterial Viability Kit. Ann Agric Environ Med 2014, 21, 35-41.

4. Dors A., Czyżewska E., Pomorska-Mól M., Kołacz R., Pejsak Z.: Effect of various husbandry conditions on the production parameters of swine herds in Poland. Pol J Vet Sci 2013, 16, 707-713.

5. Dors A., Pomorska-Mól M., Czyżewska E., Wasyl D., Pejsak Z.: Prevalence and risk factors for Lawsonia intracellularis, Brachyspira hyodysenteriae and Salmonella spp. in finishing pigs in Polish farrow-to-finish swine herds. Pol J Vet Sci 2015, 18, 825-831.

6. Eijck I.A., Borgsteede F.H.: A survey of gastrointestinal pig parasites on free-range, organic and conventional pig farms in the Netherlands. Vet Res Commun 2005, 29, 407-414.

7. Fudalewicz-Niemczyk W., Nowosad B.: Robaczyce przewodu pokarmowego u świń w różnych typach ferm na terenie Polski południowej. Zeszyty Nauk AR Kraków Zoot 1988, 26, 63-71.

8. Gerwert S., Failing K., Bauer C.: Husbandry management, worm control practices, and gastro-intestinal parasite infections of sows in pig-breeding farms in Münsterland, Germany. Dtsch Tierarztl Wochenschr 2004, 111, 398-403.

9. Helwigh A.B., Christensen C.M., Roepstorff A., Nansen P.: Concurrent Ascaris suum and Oesophagostomum dentatum infections in pigs. Vet Parasitol 1999, 82, 221-234.

10. Jankowska-Mąkosa A., Knecht D.: The influence of endoparasites on selected production parameters in pigs in various housing systems. Res Vet Sci 2015, 100, 153-160.

11. Joachim A., Dülmer N., Daugschies A., Roepstorff A.: Occurrence of helminths in pig fattening units with different management systems in Northern Germany. Vet Parasitol 2001, 96, 135-146.

12. Karamon J., Ziomko I., Cencek T.: Prevalence of Isospora suis and Eimeria spp. in suckling piglets and sows in Poland. Vet Parasitol 2007, 147, 171-175.

13. Kłapeć T., Borecka A.: Contamination of vegetables, fruits, and soil with geohelminth eggs on organic farms in Poland. Ann Agric Environ Med 2012, 19, 421-425.

14. Kłapeć T., Cholewa A.: Health risk associated with the use of organic and organic-mineral fertilizers. Med Og Nauk Zdr 2012, 18, 131-136.

15. Knecht D., Popiołek M., Zaleśny G.: Does meatiness of pigs depend on the level of gastro-intestinal parasites infection? Prev Vet Med 2011, 99, 234-239.

16. Lai M., Zhou R.Q., Huang H.C., Hu S.J.: Prevalence and risk factors associated with intestinal parasites in pigs in Chongqing, China. Res Vet Sci 2011, 91, 121-124. doi: 10.1016/j.rvsc. 2011.01.025

17. Matsubayashi M., Kita T., Narushima T., Kimata I., Tani H., Sasai K., Baba E.: Coprological survey of parasitic infections in pigs and cattle in slaughterhouse in Osaka, Japan. J Vet Med Sci 2009, 71, 1079-1083.
18. Mejer H., Roepstorff A.: Ascaris suum infections in pigs born and raised on contaminated paddocks. Parasitology 2006, 133, 305-312.

19. Mercy A.R., de Chaneet G., Emms Y.: Survey of internal parasites in Western Australian pig herds. 1. Prevalence. Aust Vet J 1989, $66,4-6$.

20. Michalski M.M.: Economic losses caused by parasite invasions in animals and methods of their evaluation. Med Weter 2007, 63, 643-647.

21. Nansen P., Roepstorff A.: Parasitic helminths of the pig: factors influencing transmission and infection levels. Int J Parasitol 1999, 29, 877-891.

22. Nosal P., Eckert R.: Gastrointestinal parasites of swine in relation to the age group and management system. Med Weter 2005, 61, 435-437.

23. Nosal P., Petryszak A., Nowosad B.: Some aspects of nematode infection in pigs from small herds. Pol J Vet Sci 2008, 11, 219-223.

24. Petersen H.H., Andreasen A., Kringel H., Roepstorff A., Thamsborg S.M.: Parasite population dynamics in pigs infected with Trichuris suis and Oesophagostomum dentatum. Vet Parasitol 2014, 199, 73-80.

25. Połozowski A., Zieliński J., Zielińska E.: Influence of breed conditions on presence of internal parasites in swine in small-scale management. EJPAU 2005, 8, (http://www.ejpau.media.pl/ new/veterinary/volume8/issuel/index.html).

26. Popiołek M., Knecht D., Boruta O., Kot M.: Effect of breeding conditions, phenology, and age on the occurrence of helminths in pigs. A preliminary study. Bull Vet Inst Pulawy 2009, 53, 213-220.

27. Raynaud, J.P.: Etude de l'efficacited'une technique de coproscopie quantitative pour le diagnostic de routine et le controle des infestations parasitaires des bovins, ovins, equines et porcins. Ann Parasitol (Paris) 1970, 45, 321-342.

28. Regulation of Polish Minister of Agriculture and Rural Development of 18 June 2008 implementing some provisions of the fertilizers and fertilizing act. Journal of Laws 2008, Nr 119 , item 765 .

29. Reiczigel J., Rozsa L., Reiczigel A., Fabian I.: Quantitative Parasitology (QPweb), 2013, http://www2.univet.hu/qpweb.

30. Roepstorff A., Nilsson O., Oksanen A., Gjerde B., Richter S.H., Ortenberg E., Christensson D., Martinsson K.B. , Bartlett P.C., Nansen P., Eriksen L., Helle O., Nikander S., Larsen K.: Intestinal parasites in swine in the Nordic countries: prevalence and geographical distribution. Vet Parasitol 1998, 76, 305-319.

31. Roepstorff A., Murrell K. D., Boes J., Petkevicius S.: Ecological influences on transmission rates of Ascaris suum to pigs on pastures. Vet Parasitol 2001, 5, 143-153.

32. Sergeant, ESG, 2017. Epitools epidemiological calculators. Ausvet Pty Ltd., http://epitools.ausvet.com.au.

33. Smets K., Neirynck W., Vercruysse J.: Eradication of sarcoptic mange from a Belgian pig breeding farm with a combination of injectable and in-feed ivermectin. Vet Rec 1999, 145, 721-724.

34. Stefański W., Żarnowski E.: Rozpoznawanie inwazji pasożytniczych u zwierząt, PWRiL, Warszawa, 1971.

35. Stępień S.: Structural changes in the pigmeat sector in selected European union countries. JARD 2014, 1, 133-141.

36. Thamsborg S.M., Roepstorff A., Larsen M.: Integrated and biological control of parasites in organic and conventional production systems. Vet Parasitol 1999, 84, 169-186.

37. Utnik-Banaś K.: The structure of farms specialising in pig production in Poland. PDGR-PSAH 2015, 2, 69-80. doi: http://dx.doi.org/10.15576/PDGR/2015.2.69.

38. Weng Y.B., Hu Y.J., Li Y., Li B.S., Lin R.Q., Xie D.H., Gasser R.B., Zhu X.Q.: Survey of intestinal parasites in pigs from intensive farms in Guangdong Province, People's Republic of China. Vet Parasitol 2005, 127, 333-336.

39. Zdybel J., Cencek T., Karamon J., Kłapeć T.: Effectiveness of selected stages of wastewater treatment in elimination of eggs of intestinal parasites. Bull Vet Inst Pulawy 2015, 59, 51-57. 